\title{
DESENVOLVIMENTO DE APLICAÇÕES TECNOLÓGICAS NA FORMA PRÉ- GELATINIZADA PARA GRÃOS DE QUINOA (Chenopodium quinoa Willd)
}

\author{
DEVELOPMENT OF TECHNOLOGICAL APLICATION AS PREGELATINIZER \\ TO QUINOA GRAINS
} (Chenopodium quinoa Willd)

\author{
DEGÁSPARI, Cláudia Helena ${ }^{1 *}$, SILVA, Noelaine Martins ${ }^{2}$ \\ ${ }^{1}$ Professora Adjunta da Universidade Tuiuti do Paraná. \\ R. Com. Fontana, 405, ap. 803-80030-070 - Curitiba - PR \\ e-mail: sensus@cwb.matrix.com.br \\ ${ }^{2}$ Nutricionista da Sodexo do Brasil Com. Ltda \\ e-mail: noelaine@bol.com.br
}

REC: $10 / 09$ AC: $11 / 09$

\begin{abstract}
RESUMO:
Este trabalho teve como objetivo desenvolver um produto alimentício pré-gelatinizado, na forma de flocos à base de grãos de quinoa (Chenopodium quinoa Willd) a partir de grãos da variedade BRS Piaburu, desenvolvido pela EMBRAPA Cerrados. Os grãos foram submetidos a dois processos distintos: no primeiro processo houve intumescimento dos grãos com água em excesso a temperatura ambiente por 24 horas, com troca da água para retirada das saponinas, moídos em moinhos de disco, peneirados em peneira circular com abertura de $1,6 \mathrm{~mm}$, espalhados em equipamento floculador específico com movimento circular (chapa de ferro aquecida a uma temperatura de $200^{\circ} \mathrm{C}$ ), sendo desidratados e removidos da chapa através de uma operação de raspagem. Com isso, obtiveram-se flocos de $0,5 \mathrm{~mm}$ de espessura e diâmetro variando de 15 a $20 \mathrm{~mm}$ com coloração parda, textura homogênea e sabor levemente caramelizado, porém não pré-gelatinizado. No segundo processo, os grãos foram apenas umedecidos (sem troca da água), passando pela mesma sequência de operações unitárias, obtendo-se flocos de $2 \mathrm{~mm}$ de espessura e diâmetro de 30 a 40 $\mathrm{mm}$, com coloração parda e textura não homogênea, com pouca agregação e leve sabor amargo residual. Os flocos obtidos no primeiro processo não foram drageados devido à sua baixa densidade, enquanto que os obtidos no segundo processo foram com uma solução de sacarose, cloreto de sódio, ácido cítrico e aroma de baunilha, mas o resultado final não foi satisfatório, pois não foi possível disfarçar o gosto amargo dos flocos. Ambos os produtos obtidos não foram avaliados sensorialmente por não apresentarem características sensoriais e de funcionabilidade adequadas ao consumidor. Desta forma, observa-se que é possível obter produtos com emprego de processos tecnológicos diversos a partir da quinoa do Cerrado (Chenopodium quinoa Willd variedade BRS Piabiru). Entretanto, é necessário que se aplique e desenvolva um processo tecnológico adequado de forma a minimizar o efeito sensorial amargo devido ao seu teor de saponina para seu consumo satisfatório. Não foram realizadas as planilhas de custo de produção e comercialização.

Palavras-chave: quinoa BRS Piaburu; flocos de cereais; produtos matinais; Chenopodium quinoa Willd.
\end{abstract}

\footnotetext{
ABSTRACT

This research had as objective develops a pré-gelatinized nutritious product, in the form of flakes from quinoa Chenopodium quinoa Willd grains, starting from grains of the variety
} 
BRS Piaburu, developed by EMBRAPA Cerrados Institut. The grains were submitted to two different processes: An intumesciment occured at first step of the grains with water in excess to room temperature for 24 hours, with change of the water to remove of the saponin, milled in disk mills, drizzled in circular sieve with opening of $1,6 \mathrm{~mm}$, dispersed in equipment specific flaker with circular movement (warm sheet iron the at $t 200{ }^{\circ} \mathrm{C}$ ), being dehydrated and removed of the foil through a scratching operation. It was obtained flakes of $0,5 \mathrm{~mm}$ of thickness and diameter slightly varying from 15 to $20 \mathrm{~mm}$ with brown coloration, homogeneous texture and flavor carameled, but not pré-gelatinized. In the second process, the grains were just moistened (without change of the water), going by the same sequence of unitary operations, obtaining flakes of $2 \mathrm{~mm}$ of thickness and diameter from 30 to $40 \mathrm{~mm}$, with brown coloration and texture no homogeneous, with little aggregation and bitter flavor. The flakes obtained in the first process were not drageaded due to his low density, while obtained them in the second process were with a sucrose solution, sodium chloride, citric acid and vanilla flavor, but the final result was not satisfactory, because was not possible to bitter taste of the flakes. Both final products were not evaluated sensorialy because they don't present sensorial characteristics and appropriate funcionability to the consumer. This way, is observe that is possible to obtain products with job of several technological processes starting from the quinoa of the Cerrado (Chenopodium quinoa Willd variety BRS Piabiru). However, it is necessary that it is applied and develop an appropriate technological process in way to minimize the bitter sensorial effects due to the saponin tenor for a satisfactory consumption. The worksheets of production cost and commercialization were not been implemented.

Key words: quinoa BRS Piaburu; cereal flakes; breakfast products; Chenopodium quinoa Willd.

\section{INTRODUÇÃO}

A alimentação saudável deve fornecer ao organismo todos os nutrientes que supram a necessidade do indivíduo. Portanto, as refeições devem ser diversificadas para que contenham todos os nutrientes: carboidratos, proteínas, lipídios, fibras, vitaminas e sais minerais.

Atualmente, cada vez mais fica difícil a alimentação adequada e balanceada. Para facilitar a vida de muitas pessoas, diversos produtos são desenvolvidos constantemente de forma a atender às necessidades de praticidade, facilidade de obtenção, bom valor nutricional agregado e preço acessível.

As pesquisas na área agropecuária vêm ocorrendo no sentido de se desenvolver espécies geneticamente adaptadas às características de cultivo ou criação do território brasileiro. Uma destas espécies ou culturas é o pseudocereal denominado de quinoa (Chenopodium quinoa Willd), que apresenta um melhor valor nutricional quando comparado com o arroz, a cevada, o milho e o trigo. Da mesma espécie do espinafre e da beterraba, é uma granífera domesticada há milhares de anos pelos povos andinos (SPEHAR \& SANTOS, 2002)

Para SPEHAR e SOUZA (1993) a quinoa contém maior quantidade de proteína, mais equilíbrio na distribuição de aminoácidos essenciais que os cereais e assemelha-se à caseína - fração protéica do leite.

Seguindo SPEHAR e SANTOS (2002), isso tem contribuído para a popularização da quinoa entre as pessoas que buscam alimentos alternativos com alto valor nutritivo e baixo colesterol, em especial à da caseína, fração protéica do leite. Na região andina, onde o grão é muito difundido, as crianças, depois do desmame, passam a consumi-la na forma de papas ou mingaus, como tradicionalmente são preparados os alimentos infantis em outras regiões do mundo. 
Por sua vez, os adultos podem preparar vários pratos, nos quais a quinoa contribui para melhorar a qualidade nutricional da dieta e realçar o sabor típico de cereal. Usam-na ainda, como suplemento na dieta de idosos e de convalescentes. Cita-se também seu emprego em regimes especiais para pacientes celíacos (SPEHAR \& SANTOS, 2002). A doença celíaca é causada pela intolerância ao glúten, uma proteína encontrada no trigo, aveia, triticale, cevada, centeio e seus derivados. Alguns dos sintomas apresentados para a doença são: diarréia com perda de gordura e sangue nas fezes, vômito, perda de peso, inchaço nas pernas entre outros. Neste caso de patologia nutricional, o único tratamento é uma dieta exclusivamente sem glúten, ou seja, totalmente ausente dos cereais que contenham esta proteína na sua constituição: trigo, centeio, triticale, cevada e aveia (ANVISA, 1992; ANVISA, 2002). Isto acaba tornando a alimentação destas pessoas um pouco limitada.

Em contrapartida, hoje no mercado, encontram-se diversos alimentos destinados a este público e um exemplo disso é a quinoa (Chenopodium quinoa Willd) (SPEHAR \& SANTOS, 2002).

O único inconveniente deste pequeno grão é o teor de saponina (um tipo de glicosídeo triterpenóide denominado de fraxina), que confere um sabor amargo, e que pode ser eliminada por lavagem e fricção. Antes de consumir a quinoa é necessário desaponificá-la (remover esta substância amarga ou saponina). Isso pode ser feito esfregando os grãos com as mãos em água corrente até não mais formar espuma. Após a lavagem dos grãos, os mesmos não podem ser consumidos de imediato, pois devem ser secos, visto que a quinoa úmida germina rapidamente. (CHUMPITAZ VIZARRETA, 2008).

Existem numerosas variedades de quinoa, são mais de 2.000 no Peru e na Bolívia, que se dividem em cinco grupos (KOKOPELLI SEED FOUNDATION, 2009):

- A quinoa dos vales: que é cultivada nos vales interandinos em altitudes entre 2.200 a 4.000 metros, sendo plantas grandes (entre 2 e 3 metros), ramificadas e se caracterizam por uma longo período de crescimento de mais de 7 meses. Esse grupo inclui variedades tais como: Blanca de Junin, Rosada de Junin, Dulce de Lazo, Dulce de Quitopamba, Amarilla de Marngani;

- A quinoa do altiplano: que é cultivada na região do Lago Titicaca a uma altitude de mais ou menos 4.000 metros. Estas variedades são particularmente resistentes à geada e atingem cerca de 1,00 a $1,80 \mathrm{~m}$ de altura, sendo que a maior parte delas não é ramificada e seu período de crescimento varia de 4 a 7 meses. Esse grupo inclui variedades tais como: Chawecca, Kanccolla, Blanca de Juli;

- A quinoa de terrenos salinos: que é originária das zonas salinas da Bolívia a uma altitude de aproximadamente 4.000 metros. Esta variedade é particularmente resistente e muito adaptada a solos salinos e muito alcalinos (com um pH acima de 8,0). Suas sementes são amargas e possuem um grande teor em proteínas, sendo, na sua grande maioria de coloração preta. Uma variedade muito adaptada a terrenos salinos foi a que deu origem à variedade Sajama, que apresenta sementes brancas e reduzido teor de saponina. Existem também algumas variedades desse grupo que apresentam sementes brancas, sendo a mais importante a que recebe a denominação comercial e popular de "Quinoa Real";

- A quinoa de zonas baixas ao nível do mar: que é cultivada ao Sul do Chile, em latitudes ao sul por volta de $40^{\circ}$. As plantas não são normalmente ramificadas e suas sementes amarelas e translúcidas são amargas. Atinge uma altura de aproximadamente 2 metros, sendo plantas que florescem em dias longos (período de verão);

- A quinoa subtropical: que é cultivada nos vales interandinos da Bolívia. Apresentam uma cor verde intensa que se transforma em laranja durante o processo de maturação. Suas 
sementes podem ser brancas ou laranjas.

No entanto, a EMBRAPA - Divisão Cerrado desenvolveu uma variedade de quinoa diferenciada e adaptada às condições climáticas brasileiras. A cultivar BRS Piabiru é a primeira recomendação de quinoa como cultivo granífero no Brasil. Originou-se da linhagem EC 3, selecionada a partir de uma população procedente de Quito, Equador. Após dois anos de ensaios de competição com linhagens selecionadas anteriormente, foi uniformizada, a partir de 1998, para características agronômicas e ausência de saponina, que limita a utilização direta do grão (SPEHAR \& SANTOS, 2002).

\section{OBJETIVO}

O objetivo do trabalho foi desenvolver um produto em flocos pré-gelatinizados, apresentando um melhor valor nutricional no que diz respeito ao seu perfil de aminoácidos essenciais, sem colesterol e isento de glúten, a ser consumido puro ou com líquido (leite ou extrato protéico de soja), podendo ser recobertos com açúcar com a verificação da aceitabilidade, por meio de análise sensorial.

\section{JUSTIFICATIVA}

O trabalho se justifica à medida que produtos alimentícios são desenvolvidos com agregação de tecnologia específica, permitindo uma maior diversidade de aplicação da quinoa no setor agroindustrial.

\section{MATERIAIS E MÉTODOS}

\subsection{AMOSTRA E INSUMOS}

Este trabalho foi realizado com grãos de quinoa (Chenopodium quinoa Willd) da variedade BRS Piaburu desenvolvida pela EMBRAPA - Divisão Cerrado (Planaltina-DF-Brasil). Os grãos se encontravam livres da palha, mas não decorticados. A amostra de $10 \mathrm{Kg}$ foi doada pelo produtor Engenheiro Agrônomo Sebastião Conrado de Andrade, da Fazenda Dom Bosco (Cristalina-GO-Brasil), pioneiro nessa cultura, sendo que a primeira safra comercial dos grãos foi em 2002.

Para o drageamento, foram utilizadas as seguintes matérias-primas para obtenção da solução de aspersão: açúcar refinado marca comercial União, sal refinado marca comercial Diana, ácido cítrico anidro fino marca Mercocítrico Fermentações da Tate \& Lyle e aroma líquido de baunilha marca Mix Indústria de Produtos Alimentícios.

\subsection{EQUIPAMENTOS}

Os pesquisadores tentaram inicialmente se utilizar dos equipamentos disponíveis nos laboratórios da Universidade Tuiuti do Paraná e propostos inicialmente no Projeto de Pesquisa, com pequenas amostras dos grãos (aproximadamente 70 gramas): fogão convencional e estufa com e sem circulação de ar. No entanto, os testes iniciais com tais equipamentos não se mostraram favoráveis de forma a se obter um produto com boas características sensoriais e que pudesse ser reproduzido posteriormente em escala industrial. 
Com isso, procurou-se por um apoio tecnológico em outra área de processamento de alimentos e, por gentileza do industrial Sr. Marcos Szychta, foi possível a realização dos ensaios numa agroindústria na cidade de Campo Largo, região metropolitana de Curitiba PR, denominada de Moinho Dom Pedro. A referida agroindústria produz derivados de milho branco e amarelo na forma de flocos (farinha de milho) e na forma pulverizada (fubá de milho). Os equipamentos utilizados foram: tanque para intumescimento dos grãos, moinho de disco, despolpador com peneira de abertura de 1,6 mm (peneira $14 \mathrm{GG}$ ), chapa de ferro circular rotatória com diâmetro de aproximadamente 5 metros, aquecida através da queima de cepilho, contendo rolos compressores de teflon resistente e posteriormente embalado por embaladora vertical, com cabeçote de selagem para filme em polietileno.

O equipamento drageador utilizado na segunda porção da amostra foi Drageador tipo Tangerina, marca Lawes.

\subsection{ANÁLISE SENSORIAL}

Os produtos finais obtidos seriam submetidos a testes de análise sensorial de aceitabilidade empregando-se o método de escala hedônica com nove pontos (AMERICAN SOCIETY FOR TESTING AND MATERIALS, 1973; AMERINE, PANGBORN \& ROESSLER, 1965), sendo o valor máximo 9 (gostei muitissímo) e o mínimo 1 (desgostei muitíssimo). Esta etapa de degustação do protótipo obtido foi aprovada pelo Comitê de Ética em Pesquisa em Humanos e Animais da Universidade Tuiuti do Paraná (CEP-UTP $n^{\circ}$ 000015/2009). (ANEXO 01).

As pessoas selecionadas para a realização dos testes seriam escolhidas aleatoriamente, sendo a amostra composta por acadêmicos e funcionários da Universidade Tuiuti do Paraná. Não haveria utilização de cabines individuais específicas para aplicação de testes sensoriais, mas os mesmos seriam aplicados em laboratórios específicos da área de alimentos (Laboratório de Técnicas Dietéticas).

\section{DISCUSSÃO DOS RESULTADOS}

O objetivo inicial deste trabalho era de desenvolver um novo produto alimentício à base de grãos de quinoa na forma de flocos pré-gelatinizados que pudesse ser consumido principalmente por indivíduos que apresentem um quadro clínico de doença celíaca. Utilizou-se para tanto grãos de quinoa da variedade BRS Piaburu, desenvolvido pela EMBRAPA - Divisão Cerrado, diferenciada e adaptada às condições climáticas brasileiras. De acordo com os dados de literatura (SPEHAR \& SANTOS, 2002), os grãos apresentam ausência de saponina (um tipo de glicosídeo triterpenóide denominado de fraxina), que confere ao grão um sabor amargo, limitando sua utilização em termos sensoriais.

Os grãos recebidos foram utilizados para a elaboração de uma pasta a partir dos grãos ainda crus, que posteriormente foram submetidos a um processo de pré-gelatinização. A amostra de $10 \mathrm{Kg}$ foi dividida em duas porções de $5 \mathrm{Kg}$ e cada uma delas submetida a tratamentos iniciais diferentes antes de sofrerem o processo de pré-gelatinização.

Os testes realizados na agroindústria Moinho Dom Pedro, que produz derivados de milho branco e amarelo na forma de flocos (farinha de milho) e na forma pulverizada (fubá de milho), fez algumas adaptações no processo, de forma a se adequar às características físicoquímicas do grão de quinoa, uma vez que se trata de matérias-primas distintas. 
No caso do processamento de milho na forma de flocos, o processo se desenvolve inicialmente com os grãos sendo submetidos a um intumescimento com água em excesso a temperatura ambiente por aproximadamente 48 horas, para serem preparados para facilitar a próxima etapa de moagem. Os grãos intumescidos passam por um processo de moagem em moinho de disco, com posterior passagem em equipamento tipo despolpador, com peneira de abertura de 1,6 mm (peneira $14 \mathrm{GG}$ ) para retirada das fibras em excesso e obtenção de um produto não aglomerado, visto que se apresenta na forma umedecida. Esta etapa é importante, para que se possa passar para a etapa posterior, sendo que a massa deve se apresentar com grumos bem pequenos, quase na forma de uma farinha levemente umedecida. Após esta etapa, a massa é espalhada, com o auxílio de rolos compressores de teflon resistente, em uma grande chapa de ferro circular rotatória, aquecida através da queima de cepilho (restos de madeira com maior granulometria que a serragem convencional. Neste caso convém ressaltar que se trata de uma agroindústria, onde os custos devem ser minimizados bem como o sistema tende ser o mais artesanal possível, porém com os mesmos cuidados higiênico-sanitários de uma indústria convencional de alimentos), a uma temperatura superior a $200^{\circ} \mathrm{C}$. Com isso, a massa, em contato com a chapa aquecida, transforma-se rapidamente em flocos, desidratados, com formato oval ou arredondado e poroso, soltando-se facilmente da chapa, ocorrendo em seguida apenas de um processo de recolhimento do material final por coleta, sem necessidade de atrito ou raspagem da chapa. Após, o produto é embalado em sacos de polietileno e comercializado, apresentando um prazo de validade de oito meses devido à baixa atividade de água.

No caso dos grãos de quinoa, ambas as porções foram submetidas a este mesmo processo empregado para o milho (exceto o intumescimento), ou seja: intumescimento para a primeira porção de amostra de $5 \mathrm{Kg}$ e umidificação para a segunda porção de amostra de $5 \mathrm{Kg}$, moagem, secagem, recolhimento do material e embalagem. As características físico-químicas e sensoriais dos produtos finais obtidos serão descritas a seguir.

A primeira porção foi submetida a um processo de intumescimento dos grãos com água em excesso a temperatura ambiente por aproximadamente 24 horas, sendo trocada a água por 5 vezes até que se reduzisse o teor de saponina, que confere ao grão um sabor amargo desagradável. Isto é observado através do aparecimento de espuma na superfície da água de lavagem. A absorção de água pelos grãos foi de aproximadamente $8 \%$ ( $800 \mathrm{~mL}$ de água absorvido para cada $1 \mathrm{Kg}$ de grãos). No entanto, esta absorção pelos grãos de quinoa foi muito maior que no caso do milho. Devido a isso, os grãos se apresentaram muito macios e com alta umidade o que dificultou o processo de peneiramento. Obteve-se, ao final deste processo, uma massa viscosa e muito umedecida, muito diferente à que se obtém para o milho. Mesmo assim, deu-se prosseguimento ao teste e aplicou-se a massa na chapa rotatória quente com o auxílio dos rolos compressores. Porém, ao contrário do milho que se desprende facilmente da chapa tornando-se flocos, a massa de quinoa aderiu à chapa e foi retirada a seguir por raspagem da superfície com o auxílio de uma lâmina. O produto final obtido foram flocos de $0,5 \mathrm{~mm}$ de espessura e diâmetro variando de 15 a $20 \mathrm{~mm}$, com coloração parda, textura homogênea e sabor levemente caramelizado e agradável. De acordo com esta descrição, pode-se perceber que o produto apresentava características semelhantes a uma "farinha láctea". No entanto, como era de se esperar, a massa amilácea destes flocos não gelanitizou e, portanto, seu poder de absorção de líquidos a frio, não ocorreu, tampouco resultou num aumento da viscosidade da solução, que é a característica básica de um produto pré-gelatinizado. Por outro lado, como estes flocos apresentaram uma baixa densidade $\left(0,20 \mathrm{~g} / \mathrm{cm}^{3}\right)$, os mesmos não foram drageados, pois o drageador é provido de um fluxo de ar quente, que faz com que os flocos

Visão Acadêmica, Curitiba, v.11, n.1, Jan. - Jun./2010 - ISSN 1518-5192 
leves se dispersem para fora dele.

Com isso, não se procedeu a sua avaliação de aceitabilidade sensorial com um modo de apresentação de uma "farinha láctea": um mingau com leite e açúcar, nem de outra forma, pois não se vislumbrou uma possível aplicação comercial para este produto.

Na segunda porção de $5 \mathrm{Kg}$, os grãos foram submetidos a um processo de umidificação (sem provocar o intumescimento dos grãos), ou seja, os grãos ficaram $100 \%$ submersos por 10 minutos em água na temperatura ambiente. No caso, o teste com esta porção, não submeteu os grãos a um processo de lavagem ou troca de água. Esta medida foi adotada visto que, de acordo com a experiência do proprietário da agroindústria, num processo em escala industrial, o gasto com água seria demasiado, podendo torná-lo inviável em termos de custos finais. Mesmo não ficando por muito tempo em água, os grãos se apresentaram macios, possibilitando a realização do processo de moagem sem dificuldades. Após esta etapa, os grãos passaram pela mesma sequência de operações unitárias. Neste caso, não houve aderência da massa à chapa quente, sendo obtido um produto final em flocos de $2 \mathrm{~mm}$ de espessura e diâmetro de 30 a $40 \mathrm{~mm}$, com densidade de $2,00 \mathrm{~g} / \mathrm{cm}^{3}$, com coloração parda e textura não homogênea, com pouca agregação da massa seca e leve sabor amargo residual. Mesmo com todas estas características pouco favoráveis, os flocos sofreram um processo de drageamento, com o intuito de disfarçar (ou "fazer uma bonificação") o gosto amargo do mesmo. A solução de drageamento foi elaborada na seguinte proporção:

- $1.000 \mathrm{~mL}$ de água fria

- $1.000 \mathrm{~g}$ de sacarose

- $50 \mathrm{~g}$ de cloreto de sódio

- $15 \mathrm{~g}$ de ácido cítrico

- $30 \mathrm{~mL}$ de essência de baunilha

A solução foi aspergida sobre os flocos no equipamento drageador com rotação e insuflamento de ar quente contínuo por aproximadamente 1 hora. O resultado final foi relativamente satisfatório, conseguindo-se encobrir boa parte do gosto amargo dos flocos. $A$ presença e permanência deste gosto amargo, possivelmente se deve à não retirada da saponina pelos seguidos processos de lavagem dos grãos. Isso vai contra o que se relata na literatura sobre o grão desenvolvido pela EMBRAPA - Divisão Cerrado, visto que o gosto amargo não foi possivelmente eliminado por melhoria genética (SPEHAR \& SANTOS, 2002).

Neste caso, também não se realizou o teste de análise sensorial de aceitabilidade, pois o resultado seria, com certeza, desfavorável. Isto porque, o gosto amargo causa aversão ao ser humano, pois pode ser indicativo do grau de toxicidade de um alimento. Excessivos graus de amargor caracterizam a rejeição ao consumo, conforme verificado por FISCHER et al. (1961). Isto é coerente, pois a maioria dos alcalóides, quando ingeridos em altas concentrações, se mostra tóxicos ao organismo, como por exemplo, a morfina e a estricnina (FENWICK et al., 1990; ROBINS et al., 1990). É por esta razão que os seres humanos, desde cedo, evitam frutas, folhas e raízes que apresentem esta característica sensorial (BRIESKORN, 1990).

Com isso, de acordo com os ensaios realizados com os grãos observou-se que é possível a obtenção de produto tipo flocos (finos e grossos) a partir de um equipamento simples e perfeitamente viável a uma agroindústria de secagem e flocagem da massa, desde que os grãos desta variedade testada sofram um processo de lavagens consecutivas para eliminação da saponina, porém esta etapa pode deixar os grãos muito macios, dificultando as etapas posteriores. Por outro lado, há a necessidade de realização de mais testes de forma a obter um produto mais agregado e que seja físico-quimicamente pré-gelatinizado e apresente 
características sensoriais e de funcionabilidade adequadas ao consumidor.

Há também a necessidade de elaboração de planilhas de custo de produção e comercialização para se verificar a viabilidade econômica do processo como um todo (incluindo custos da matéria-prima, produção e comercialização). Porém, isso não fazia parte dos objetivos deste trabalho, sendo que caberia a um novo projeto de pesquisa distinto, devido à sua complexidade.

Fazendo uma correlação com o produto que se apresenta no mercado varejo nacional na forma in natura ou simplesmente flocado (processo de amassamento do grão sem submetêlo a qualquer processo tecnológico mais complexo ou com a aplicação em formulações elaboradas), cabe ressaltar que o mesmo é obtido a partir de "Quinoa Real" (Chenopodium quinoa Willd, variedade Sajama, com sementes brancas e fraco teor de saponina). A "Quinoa Real", um produto importado e geneticamente diferente do que foi utilizado nesta pesquisa, apresenta teor de saponina praticamente nulo (observado através de degustação e por meio do teste de lavagem, onde não ocorre a formação da espuma característica da saponina), o que viabiliza seu consumo até mesmo in natura. No entanto, caso a pesquisa realizada utilizasse a matéria-prima atualmente disponível no mercado nacional ("Quinoa Real"), o projeto seria inviável devido ao alto preço desta matéria-prima.

\section{CONCLUSÕES}

Assim sendo, observa-se que é possível obter produtos com emprego de processos tecnológicos diversos a partir da quinoa do Cerrado (Chenopodium quinoa Willd variedade BRS Piabiru). Entretanto, é necessário que se aplique e desenvolva um processo tecnológico adequado de forma a minimizar os efeitos sensoriais amargos devido ao seu teor de saponina para seu consumo satisfatório.

Devido ao curto tempo e à pequena quantidade de amostra disponível, não foi possível desenvolver um produto final com boa aceitabilidade e aplicabilidade mercadológica.

Para tanto, serão necessários diversos ensaios tecnológicos até que se obtenha um produto com boas características sensoriais e que possa ser reproduzido posteriormente em escala industrial.

\section{REFERÊNCIAS}

AMERICAN SOCIETY FOR TESTING AND MATERIALS. Basic principles of sensory evaluation. 3rd. ed. Philadelphia: American Society for Testing and Materials, 1973.

AMERINE, M. A.; PANGBORN, R. M.; ROESSLER, E. B. Principles of sensory evaluation of food. London : Academic Press, 1965.

BRASIL, ANVISA. Lei n 8543 de 23 de dezembro de 1992. Disponível em: <http://elegis.anvisa.gov.br/leisref/public/showAct.php?id=32>. Acessado em: 03 dez. 2008.

BRASIL, ANVISA. Resolução - RDC n 40 de 8 de fevereiro de 2002. Disponível em: <http://anvisa.gov.br/legis/resol/40_02rdc.htm>. Acessado em: 03 dez. 2008.

BRIESKORN, C. H. Physiological and therapeutical aspects of bitter compounds. In: ROUSEFF, R. L. Bitterness in foods and beverages. Amsterdam : Elsevier, 1990. 
CHUMPITAZ VIZARRETA, Omar Antonio. Posición de la quinua en el mercado. Disponível em: <http://www.monografias.com:80/trabajos35/quinua/quinua.shtml>. Acessado em 11 jun. 2008.

FENWICK, G. R. et al. Bitter principles in food plants. In: ROUSEFF, R.L. Bitterness in foods and beverages. Amsterdam : Elsevier, 1990.

FISCHER, R. et al. Taste thresholds and food dislikes. Nature, London, v.191, n.4795, Sept. 1961.

KOKOPELLI SEED FOUNDATION. Manual de sementes em português: Quinoa - Classificação botânica. Disponível em: <http://www.kokopelli-seed-foundation.com/actu/new_news.cgi?id_ news $=77>$. Acessado em: 27 nov. 2009.

SPEHAR, C.R; SANTOS, R. L. B. Quinoa (Chenopodium quinoa Willd) BRS Piabiru: alternativa para diversificar os sistemas de produção de grãos. Pesquisa Agropecuária Brasileira. Brasília: v. 37 , n. 6 , p. 889-893, 2002.

\section{AGRADECIMENTOS}

Ao produtor Engenheiro Agrônomo Sebastião Conrado de Andrade, da Fazenda Dom Bosco (Cristalina-GO-Brasil), pela doação da amostra de $10 \mathrm{Kg}$ de quinoa que permitiu a realização dos testes.

Ao Sr. Marcos Szychta proprietário da agroindústria Moinho Dom Pedro situada na cidade de Campo Largo, região metropolitana de Curitiba - PR, pela disponibilidade de realização dos testes com os grãos de quinoa. 